\title{
Investigation on Electrical Conductivity Enhancement of Water Based Maghemite $\left(\mathrm{Y}-\mathrm{Fe}_{2} \mathrm{O}_{3}\right)$ Nanofluids
}

\author{
Irwan Nurdin ${ }^{*}$, Satriananda \\ Email address: \\ irwan_nurdina@yahoo.com (I. Nurdin) \\ ${ }^{*}$ Corresponding author
}

Department of Chemical Engineering, Lhokseumawe State Polytechnic, Lhokseumawe, Indonesia

To cite this article:

Irwan Nurdin, Satriananda. Investigation on Electrical Conductivity Enhancement of Water Based Maghemite $\left(\gamma\right.$-Fe $\left.\mathrm{O}_{3}\right) \mathrm{Nanofluids}_{\text {. }}$ International Journal of Materials Science and Applications. Vol. 6, No. 1, 2017, pp. 32-36. doi: 10.11648/j.ijmsa.20170601.15

Received: October 22, 2016; Accepted: December 13, 2016; Published: January 14, 2017

\begin{abstract}
The study of this research is to measure the electrical conductivity of maghemite nanofluids. Maghemite nanofluids were prepared by dissolving maghemite nanoparticles in water as base fluids. The investigation on electrical conductivity of maghemite nanofluids have been performed at different particle volume fractions and temperatures. The electrical conductivity was measured by a 4-cell conductivity electrode meter. The electrical conductivity of maghemite nanofluids was linearly increased as the particle volume fraction and temperature rises. The highest enhancement of electrical conductivity of maghemite nanofluids due to the particle volume fraction and temperature are $160.49 \%$ and $22.55 \%$, respectively. This condition obtained at a particle volume fraction of $2.5 \%$ and temperature $60^{\circ} \mathrm{C}$. Significant effect of particle volume fraction and temperature were considered.
\end{abstract}

Keywords: Electrical Conductivity, Maghemite, Nanofluids, Nanoparticle, Volume Fraction, Temperature

\section{Introduction}

Nanofluids is a new class of engineered fluids which have contained suspended nanoparticles with their size less than $100 \mathrm{~nm}$ in the base fluids [1]. It provides more interesting application in industrial fluids system including as heat transfer, magnetic, and lubricant [2-5].

Due to their superparamagnetic behavior, maghemite nanofluids have been intensively investigated in recent year. It can be controlled using external magnetic fields [6]. With these characteristics, maghemite nanofluids performs as smart fluids which have possible for a wide range applications such as microelectronics [7], biosensor [8,9] and thermal applications [10]. They are also potential for magnetic seal, magnetic recording media [11], drug delivery or therapeutic agents in cancer therapy [12] and environmental [13].

The thermophysical and electrical properties are the important parameters in applications of these smart fluids. However, this is constraint by lack of data in the literature. Nevertheless, few data were recorded regarding thermal conductivity and viscosity of magnetite $\left(\mathrm{Fe}_{3} \mathrm{O}_{4}\right)$ nanofluids.
Numerous investigators are measured the thermal conductivity of magnetite nanofluids with the effect of particle volume fraction and temperature using different base fluids [16-19]. Their results illustrate that thermal conductivity was increased with increasing of particle volume fraction. Other researchers studied the effect of magnetic fields on thermal conductivity of magnetite nanofluids $[10,20]$. They found that the thermal conductivity of magnetite nanofluids was increased with the increasing of magnetic fields strength.

Meanwhile, researchers have also investigated the viscosity of magnetic nanofluids with respect to the particle volume fraction, temperature, and magnetic fields effect. Their results show that the viscosity of magnetite fluids was increased with the increasing of the particle volume fraction, temperature, and magnetic fields strength $[17,19]$.

Although the electrical properties of nanofluids are important parameter, study concerning this issue have been largely ignored. Lack of electrical conductivity data is available in the literature with only a few papers about the measurement of electrical conductivity of nanofluids. Ganguly [21] investigated the effective electrical conductivity of aluminum oxide nanofluids as a function of 
particle volume fraction and temperature. The results indicate that increase of electrical conductivity of aluminum oxide with increasing of particle volume fraction and temperature. Sarojini [22] conducted an experimental evaluation of electrical conductivity of ceramic and metallic nanofluids with a different volume fraction in water and ethylene glycol base fluids. The results show that the electrical conductivity of nanofluids increases with the increasing particle volume fraction in both base fluids. Electrical conductivity of magnetite nanofluids were investigated by Bagheli [15] at different volume fractions and temperatures. The result indicated considerable enhancement of electrical conductivity of magnetite nanofluids with increase of volume fraction and temperature. Recently, Zakaria [23] investigate of electrical conductivity of $\mathrm{Al}_{2} \mathrm{O}_{3}$ nanofluids in waterethylene glycol mixture. The finding shows that electrical conductivity decrease as the ethylene glycol increased. However, no investigation of electrical conductivity has been carried out for maghemite nanofluids.

In this study, the electrical conductivity of water-based maghemite nanofluids was measured at a different particle volume fractions and temperatures.

\section{Experimental}

\subsection{Nanofluids Preparation}

Maghemite nanoparticles used in this experiment have been synthesized using a chemical co-precipitation method [24]. Meanwhile, maghemite nanofluids were prepared by dissolving of maghemite nanoparticles in deionized water at different particle volume fractions $(0.5,1.0,1.5,2.0$, and $2.5 \%$ ).

The concentration of nanofluids in volume is calculated from equation below:

$$
\phi=\frac{\frac{m_{p}}{\rho_{p}}}{\frac{m_{p}}{\rho_{p}}+\frac{m_{f}}{\rho_{f}}} \times 100 \%
$$

where: $\phi$ : particle volume fraction

$m_{p}$ : mass of nanoparticles

$\rho_{p}:$ density of nanoparticles

$m_{f}$ : mass of base fluid

$\rho_{p}$ : density of base fluid

\subsection{Electrical Conductivity Measurements}

Electrical conductivity was measured by a 4-cell conductivity electrode meter (Eutech instrument PC 2700) with inbuilt automatic temperature compensation [26]. Prior to measurement, the meter was calibrated using the buffer solutions of known electrical conductivities. Measurements were performed in $30 \mathrm{ml}$ of the sample in a cylindrical glass tube with the conductivity probe immersed in it. Samples were placed and exposed to water jacketed vessel that the temperature kept constant with a JEO circulating and refrigerating water bath and allowed in the bath for 30 minutes to get the desired temperature. Measurements were conducted and repeated five times at different temperatures and particle volume fractions.

\section{Results and Discussion}

Figure 1 shows the TEM image of maghemite nanoparticles with well dispersed, uniform spherical shape and narrow particle size distribution. The average size of particle is about $9.5 \mathrm{~nm}$.

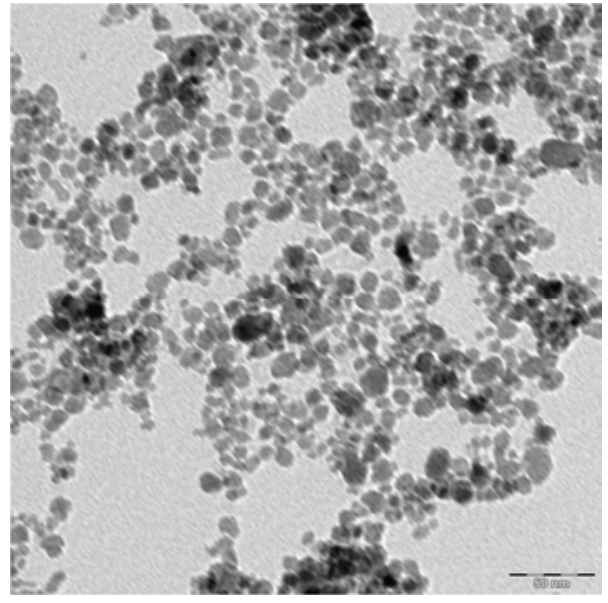

Figure 1. TEM image of maghemite nanoparticles.

Figure 2 shows the linearly increase of electrical conductivity of maghemite nanofluids at different volume fractions. The experimental data also indicates that for a given volume fraction, the electrical conductivity of the nanofluids increases with the temperature. The highest value of electrical conductivity $(14.65 \mathrm{mS} / \mathrm{cm})$ was recorded for a volume fraction of $2.5 \%$ at a temperature of $60^{\circ} \mathrm{C}$. Meanwhile, the corresponding values at room temperature $\left(30^{\circ} \mathrm{C}\right)$ was $12.52 \mathrm{mS} / \mathrm{cm}$ and the lowest temperature $\left(20^{\circ} \mathrm{C}\right)$ was $11.95 \mathrm{mS} / \mathrm{cm}$. Furthermore, these conductivity values are much higher (with ordering of 3) as compared with the electrical conductivity values of magnetite nanoparticles [15]. This probably due to the maghemite nanoparticles are more stable than magnetite nanoparticles without using any surfactant.

This phenomenon is because, the electrical conductivity of nanofluid exhibits a complicated dependence on the electrical double layer, EDL [27]. This EDL is due to the development of surface electrical charges when maghemite nanoparticles are suspended in a polar liquid. Ions with opposite charge to the particle surface are attracted are creating a charged diffuse layer around the particles. The surface charge of the particles, as well as ion-cloud that constitutes the EDL are actively plays a part in the enhancement of conduction. The existence of uniformly dispersed nanoparticles is considered by reduced equivalent particulate masses, leading to increased electrophoretic mobility. Consequently, it enhance the electrical conductivity of the maghemite nanofluids. By increasing of particle volume fraction in the solution, more conducting pathway in the solutions ere formed. That, in turn enhances the overall electrical conductivity of the solution. 


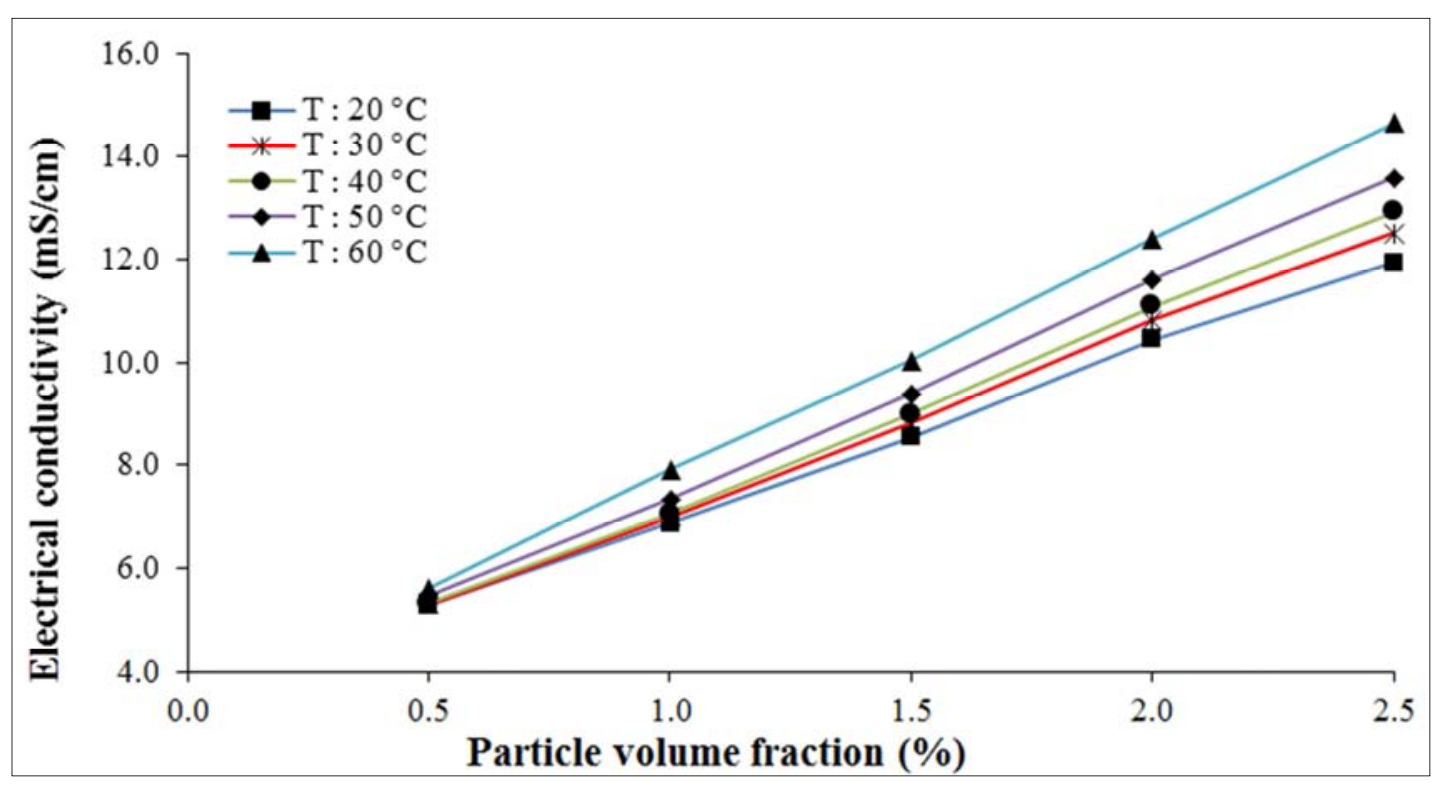

Figure 2. Electrical conductivity of maghemite nanofluids at various particle volume fraction.

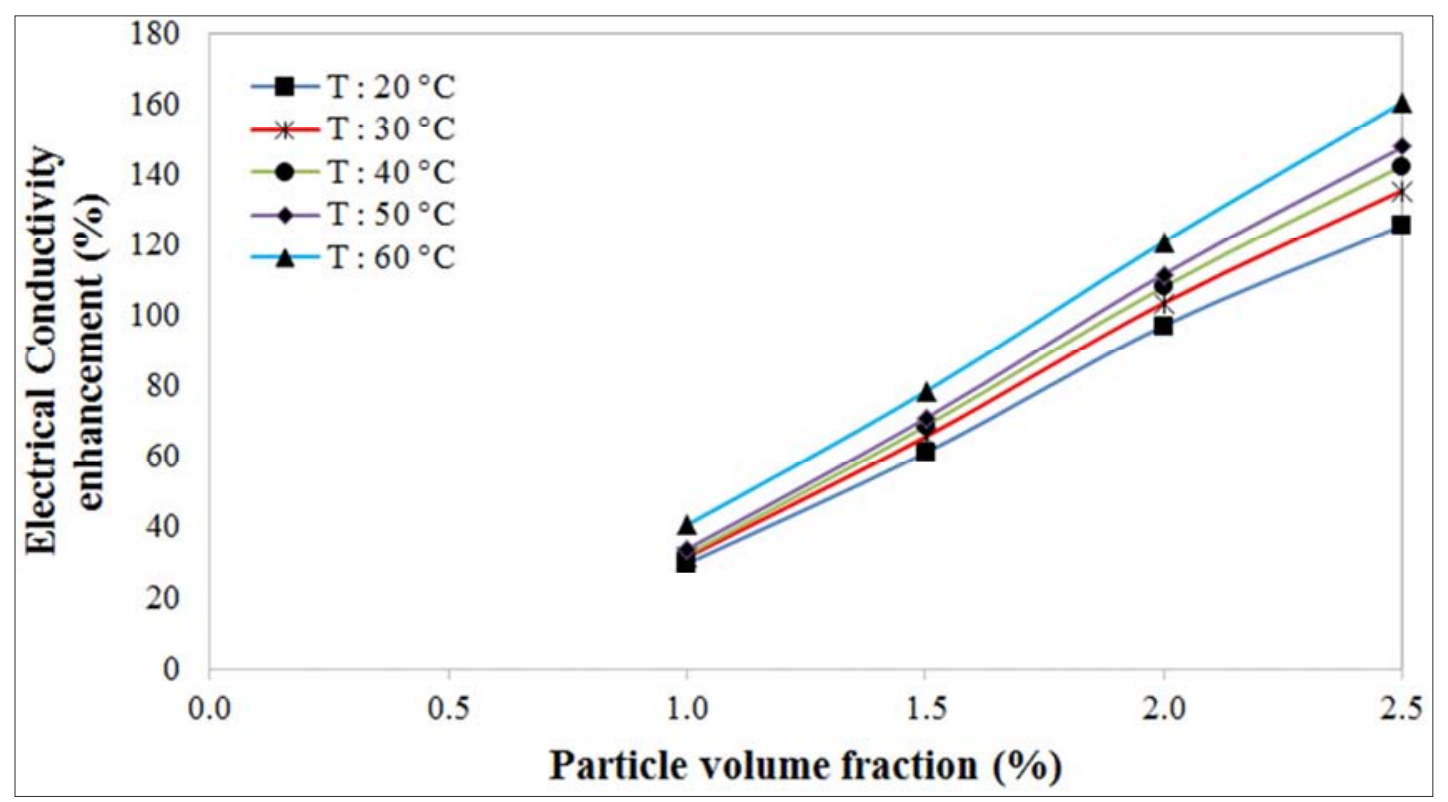

Figure 3. Enhancement of electrical conductivity of maghemite nanofluids at various particle volume fraction.

Figure 4 shows the influence of temperature on the electrical conductivity of maghemite nanofluids. The experimental data also indicate that for a given particle volume fraction, the electrical conductivity of the maghemite nanofluids increases with the temperature.

Increasing the solution's temperature will decrease its viscosity and enhance the ions mobility. Furthermore, it could also increase the number of ions in the solution due to molecules dissociation. As a result, this will lead to an increase in its conductivity.

The enhancement of electrical conductivity of maghemite nanofluid due to the temperature effect is shown in Figure 5. It is shown that the enhancement increases almost linearly with temperature. This enhancement also depends on the volume fraction as the higher the volume fraction, the greater its enhancement. A $4.73 \%$ of enhancement in the electrical conductivity was recorded at room temperature $\left(30^{\circ} \mathrm{C}\right)$ for $2.5 \%$ of volume fraction. Meanwhile, $22.55 \%$ enhancement in the electrical conductivity was recorded for the same volume fraction $(2.5 \%)$ at a temperature of $60^{\circ} \mathrm{C}$. The electrical conductivity enhancement of maghemite nanofluids due to temperature effect is lower by first order compared to volume fraction effect.

These results are in good agreement with published data on other nanofluids [21, 22, 28-32]. However, the findings do not correlate with the Maxwell [33] and Bruggeman models [34] due to these models do not take into account the increasing of temperature. This observation is also supported by Sundar [35]. 


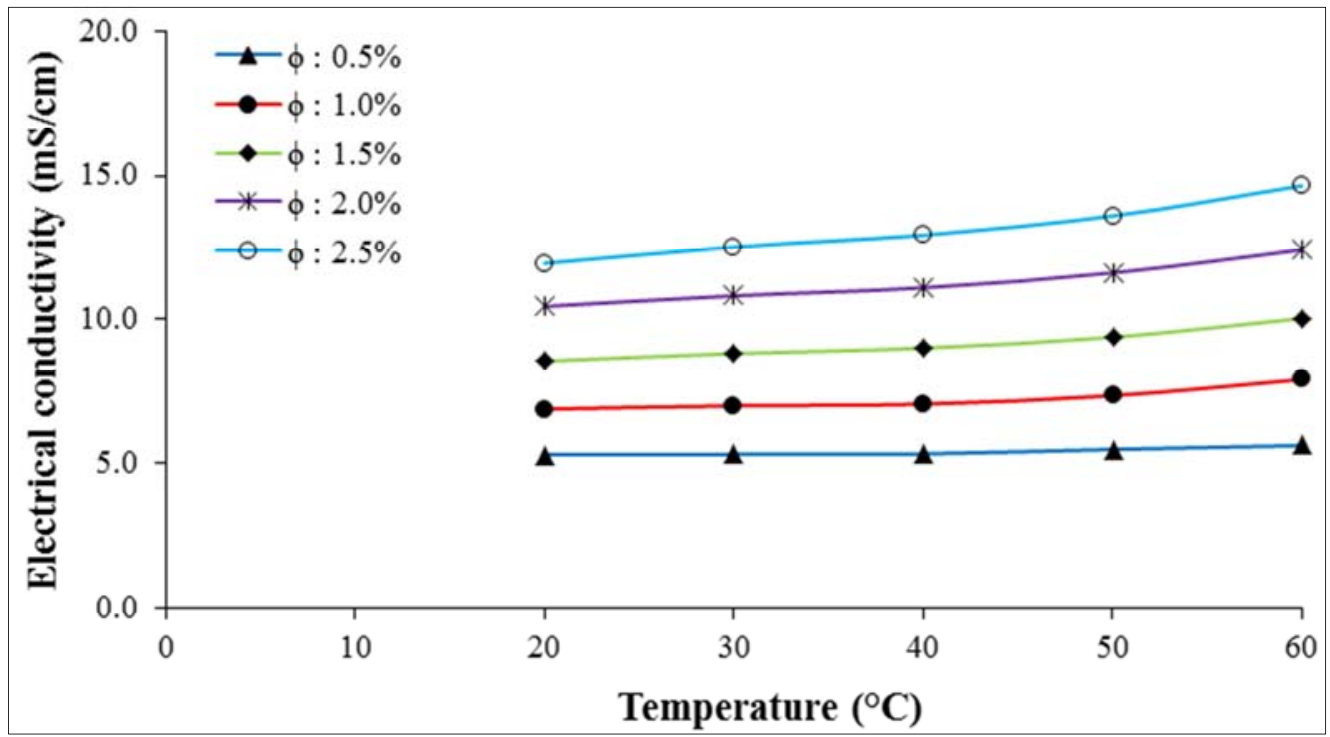

Figure 4. Electrical conductivity of maghemite nanofluids at various temperature.

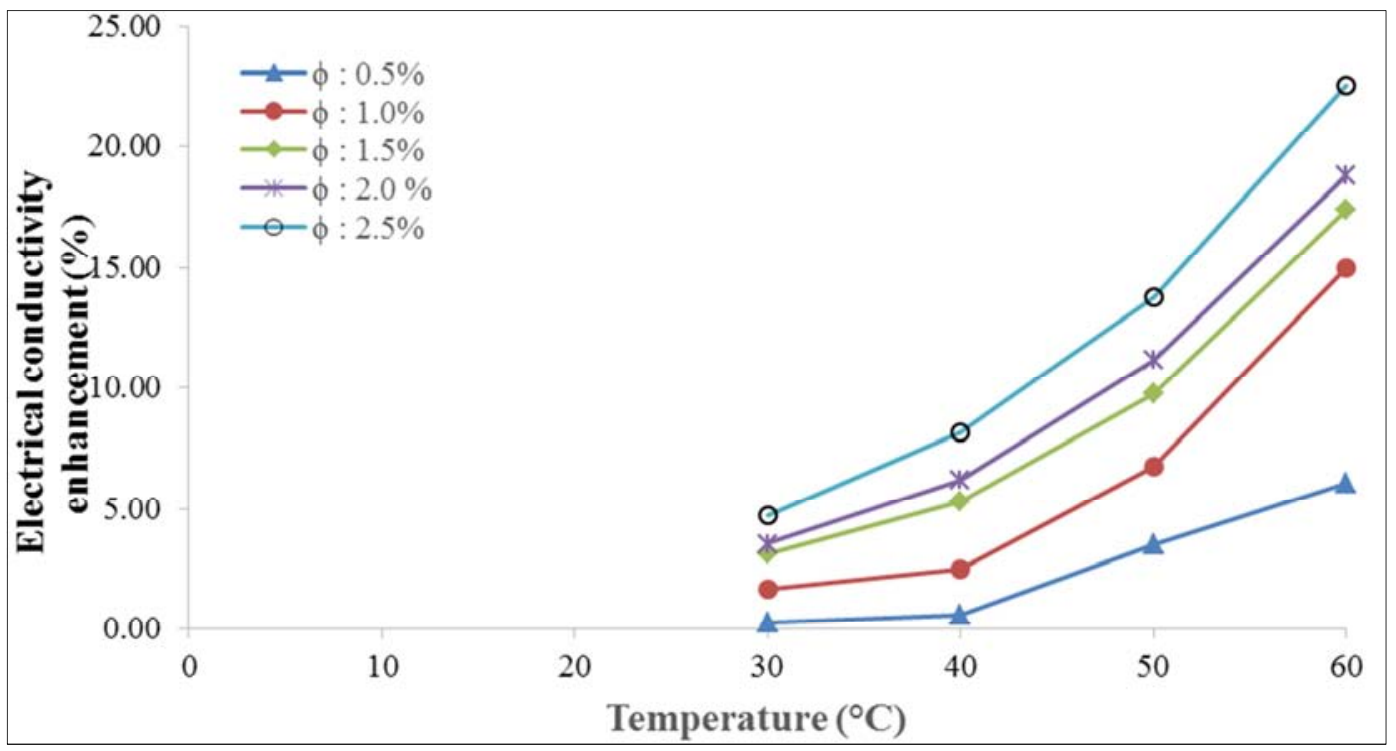

Figure 5. Enhancement of electrical conductivity of maghemite nanofluids at various temperature.

\section{Conclusion}

The investigation of electrical conductivity has been done at various particle volume fractions and temperatures. The electrical conductivity of maghemite nanofluids is almost linearly dependent with volume fraction and temperature. Increasing particle volume fraction significantly enhances the electrical conductivity of nanofluids. While the effect of temperature exhibit less significant in the enhancement of electrical conductivity of maghemite nanofluids. Higher enhancement of electrical conductivity of maghemite nanofluids is mostly achieved due to the particle volume fraction effect than temperature effect. The maximum enhancement of maghemite nanofluids is $160.49 \%$ obtained at a particle volume fraction of $2.5 \%$ and temperature of $60^{\circ} \mathrm{C}$.

\section{Acknowledgements}

This work was funded by Ministry of Research, Technology and Higher Education of the Republic of Indonesia under project no. 036/PL20/R8/SP2-PF/PL/2016.

\section{References}

[1] S. Chol, Enhancing thermal conductivity of fluids with nanoparticles, ASME-Publications-Fed 231 (1995) 99-106.

[2] Y. Hwang, J.-K. Lee, J.-K. Lee, Y.-M. Jeong, S.-i. Cheong, Y.C. Ahn, et al., Production and dispersion stability of nanoparticles in nanofluids, Powder Technol 186 (2008) 145153. 
[3] D.-H. Yoo, K. Hong, H.-S. Yang, Study of thermal conductivity of nanofluids for the application of heat transfer fluids, Thermochim. Acta 455 (2007) 66-69.

[4] K. V. Wong, O. De Leon, Applications of nanofluids: current and future, Advances in Mechanical Engineering 2010 (2010).

[5] C. T. Nguyen, G. Roy, C. Gauthier, N. Galanis, Heat transfer enhancement using $\mathrm{Al}_{2} \mathrm{O}_{3}$-water nanofluid for an electronic liquid cooling system, Appl. Therm. Eng. 27 (2007) 15011506.

[6] I. Nurdin, M. Johan, I. Yaacob, B. Ang, A. Andriyana, Synthesis, characterisation and stability of superparamagnetic maghemite nanoparticle suspension, Materials Research Innovations 18 (2014) S6-200-S6-203.

[7] S. V. Garimella, A. S. Fleischer, J. Y. Murthy, A. Keshavarzi, R. Prasher, C. Patel, et al., Thermal challenges in nextgeneration electronic systems, Components and Packaging Technologies, IEEE Transactions on 31 (4) (2008) 801-815.

[8] P. I. Nikitin, P. M. Vetoshko, T. I. Ksenevich, New type of biosensor based on magnetic nanoparticle detection, J. Magn. Magn. Mater. 311 (2007) 445-449.

[9] M. Carp, R. Müller, L. Draghiciu, R. Voicu, M. Danila, Characterization of microdevices for ferrous chloride separation for biosensing applications, Sensors and Actuators A: Physical 171 (2011) 26-33.

[10] Q. Li, Y. Xuan, Experimental investigation on heat transfer characteristics of magnetic fluid flow around a fine wire under the influence of an external magnetic field, Exp. Therm Fluid Sci. 33 (2009) 591-596.

[11] T. Tepper, F. Ilievski, C. Ross, T. Zaman, R. Ram, S. Sung, et al., Magneto-optical properties of iron oxide films, J. Appl. Phys. 93 (2003) 6948-6950.

[12] M. Namdeo, S. Saxena, R. Tankhiwale, M. Bajpai, Y. Mohan, S. Bajpai, Magnetic nanoparticles for drug delivery applications, J. Nanosci. Nanotechnol. 8 (2008) 3247-3271.

[13] K. M. Cross, Y. Lu, T. Zheng, J. Zhan, G. L. McPherson, V. T. John. Chapter 27 - Water Decontamination Using Iron and Iron Oxide Nanoparticles. In: Savage ASSD, editor. Nanotechnology Applications for Clean Water (Second Edition). Oxford: William Andrew Publishing; 2014. 423-439.

[14] E. Matijevic, R. J. Good. Surface and colloid science: Springer Science \& Business Media; 2012.

[15] S. Bagheli, H. K. Fadafan, R. L. Orimi, M. Ghaemi, Synthesis and experimental investigation of the electrical conductivity of water based magnetite nanofluids, Powder Technol. 274 (2015) 426-430.

[16] M. Abareshi, E. K. Goharshadi, S. M. Zebarjad, H. K. Fadafan, A. Youssefi, Fabrication, characterization and measurement of thermal conductivity of $\mathrm{Fe}_{3} \mathrm{O}_{4}$ nanofluids, $\mathrm{J}$. Magn. Magn. Mater. 322 (2010) 3895-3901.

[17] Q. Li, Y. Xuan, J. Wang, Experimental investigations on transport properties of magnetic fluids, Exp Therm Fluid Sci 30 (2005) 109-116.

[18] J. Philip, P. Shima, B. Raj, Enhancement of thermal conductivity in magnetite based nanofluid due to chainlike structures, Appl Phys Lett 91(20) (2007) 203108.

[19] L. S. Sundar, M. K. Singh, A. C. Sousa, Investigation of thermal conductivity and viscosity of $\mathrm{Fe}_{3} \mathrm{O}_{4}$ nanofluid for heat transfer applications, Int. Commun. Heat Mass. 44 (2013) 7-14.

[20] A. Gavili, F. Zabihi, T. D. Isfahani, J. Sabbaghzadeh, The thermal conductivity of water base ferrofluids under magnetic field, Exp. Therm Fluid Sci. 41 (2012) 94-98.

[21] S. Ganguly, S. Sikdar, S. Basu, Experimental investigation of the effective electrical conductivity of aluminum oxide nanofluids, Powder Technol. 196 (2009) 326-330.

[22] K. G. K. Sarojini, S. V. Manoj, P. K. Singh, T. Pradeep, S. K. Das, Electrical conductivity of ceramic and metallic nanofluids, Colloids and Surfaces A: Physicochemical and Engineering Aspects 417 (2013) 39-46.

[23] I. Zakaria, W. Azmi, W. Mohamed, R. Mamat, G. Najafi, Experimental Investigation of Thermal Conductivity and Electrical Conductivity of $\mathrm{Al}_{2} \mathrm{O}_{3}$ Nanofluid in Water-Ethylene Glycol Mixture for Proton Exchange Membrane Fuel Cell Application, Int. Commun. Heat Mass. 61 (2015) 61-68.

[24] I. Nurdin, M. R. Johan, I. I. Yaacob, B. C. Ang, Effect of Nitric Acid Concentrations on Synthesis and Stability of Maghemite Nanoparticles Suspension, The Scientific World Journal 2014 (2014).

[25] A. H. Lu, E.e. L. Salabas, F. Schüth, Magnetic nanoparticles: synthesis, protection, functionalization, and application, Angewandte Chemie International Edition 46 (2007) 12221244.

[26] G. Batchelor, The effect of Brownian motion on the bulk stress in a suspension of spherical particles, Journal of Fluid Mechanics 83 (1977) 97-117.

[27] G. Johnson, H. Benveniste, R. Black, L. Hedlund, R. Maronpot, B. Smith, Histology by magnetic resonance microscopy, Magnetic resonance quarterly 9(1) (1993) 1-30.

[28] A. A. Minea, R. S. Luciu, Investigations on electrical conductivity of stabilized water based $\mathrm{Al}_{2} \mathrm{O}_{3}$ nanofluids, Microfluidics and nanofluidics 13 (2012) 977-985.

[29] B. Steven, J. Albert, P. Kevin, Investigation of the electrical conductivity of propylene glycol-based $\mathrm{ZnO}$ nanofluids, Nanosca. Res. Lett 6 (2011) 346-351.

[30] L. Shen, H. Wang, M. Dong, Z. Ma, H. Wang, Solvothermal synthesis and electrical conductivity model for the zinc oxideinsulated oil nanofluid, Phys. Lett. A 376 (10) (2012) 10531057.

[31] M. Dong, L. Shen, H. Wang, H. Wang, J. Miao, Investigation on the electrical conductivity of transformer oil-based AIN nanofluid, Journal of Nanomaterials 2013 (2013) 164.

[32] S. Sikdar, S. Basu, S. Ganguly, Investigation of electrical conductivity of titanium dioxide nanofluids, International Journal of Nanoparticles 4 (2011) 336-349.

[33] J. C. Maxwell. A Treatise on Electricity and Magnetism: By James Clerk Maxwell: Dover; 1954.

[34] D. Bruggeman, Dielectric constant and conductivity of mixtures of isotropic materials, Ann Phys (Leipzig) 24 (1935) 636-679.

[35] L. S. Sundar, K. Shusmitha, M. K. Singh, A. C. Sousa, Electrical conductivity enhancement of nanodiamond-nickel (ND-Ni) nanocomposite based magnetic nanofluids, Int. Commun. Heat Mass. 57 (2014) 1-7. 